\title{
The International Classification of Functioning, Disability and Health (ICF) in Clinical Practice
}

This is a very important issue of Seminars in Speech and Language. It represents the first comprehensive attempt to discuss the World Health Organization's International Classification of Functioning, Disability and Health (ICF) in relationship to a broad conceptualization of speech-language pathology and the problems faced by individuals who are the clientele for speech-language pathologists. The issue relies on international collaborators, making it clear that relevant matters extend far beyond the boundaries of the United States. In fact, the issue editors come from Australia, Hong Kong, and the United States, and the authors are from locations throughout the world (at least its English-speaking parts and perhaps a bit more) as well.

I feel I have learned a lot as a result of helping the issue editors to put this volume together. Because all of the authors have followed similar formats, presenting initially a state-of-the-art précis of current clinical practice and ending up with a pertinent case illustration involving ICF concerns, it was possible for me to reflect on the broad issues, and the truly staggering effect the ICF should ultimately have on clinical practice in our field. It seems clear that readers of this issue should emerge from this learning experience with an equally broadening world view.

I personally want to thank Professors Linda Worrall, Estella Ma, and Travis Threats for their diligence and timeliness in managing this very broad look at our field from the important perspective of the World Health Organization. It has been a pleasure working with them.

\footnotetext{
${ }^{1}$ Department of Speech, Hearing and Language Sciences, University of Arizona, Tucson, Arizona.

The International Classification of Functioning, Disability and Health (ICF) in Clinical Practice; Guest Editors, Estella P.-M. Ma, Ph.D., Linda Worrall, Ph.D., and Travis T. Threats, Ph.D.
}

Semin Speech Lang 2007;28:239-240. Copyright (C) 2007 by Thieme Medical Publishers, Inc., 333 Seventh Avenue, New York, NY 10001, USA. Tel: +1(212) 584-4662. DOI 10.1055/s-2007-986519. ISSN 0734-0478. 